\title{
Health minister's ex-legal advisor slams Certificate of Need law
}

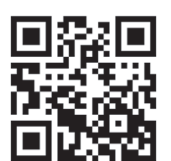

A former legal advisor to the national Minister of Health and legal expert in the medical scheme and private hospital industries, Dr Debbie Pearmain, has criticised government for 'overmanaging' healthcare service distribution and ignoring demand-side drivers.

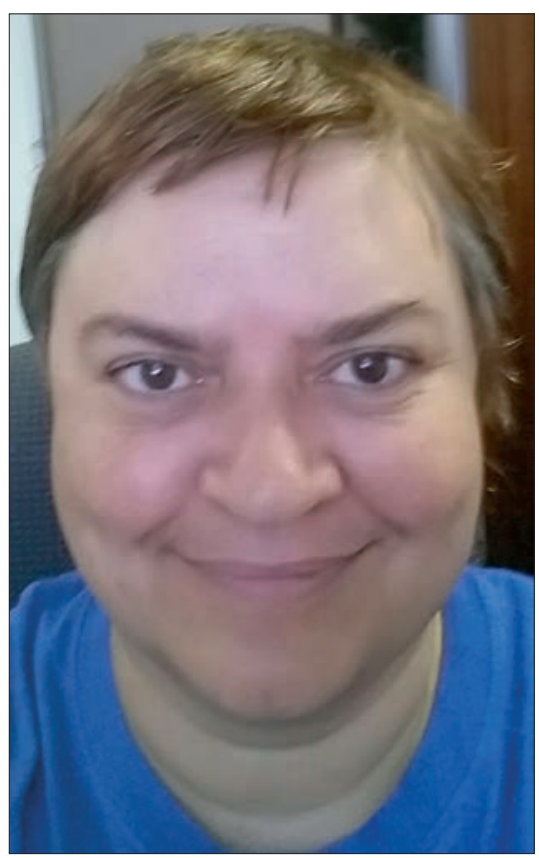

Dr Debbie Pearmain, former legal advisor to the national Minister of Health and legal expert in the medical scheme and private hospital industries.

One of several speakers who attacked the government's temporarily delayed Certificate of Need (CoN) legislation at the annual Hospital Association of South Africa (HASA) conference in Johannesburg this October, Pearmain said that health services were generally located where there was a strong likelihood of patients finding them. Yet there seemed to be no cohesive plan at national level to manage healthcare demand. Instead, a disproportionate emphasis was placed on the proposed CoN, a supply-side management tool.

The CoN legislation was temporarily put on ice earlier this year when the National Department of Health (NDoH) suddenly realised that its ambitious implementation deadline of 1 April 2016 was impractical, not to mention virtually impossible to meet. More than 70000 healthcare establishments would have had to apply for a certificate by then, not to mention tens of thousands of healthcare providers consulted via their groupings to inform regulations before they were actually drafted and published for comment. 1 April 2016 was also the date by which every single healthcare provider in the country would have had to apply to NDoH Director-General Precious Matsoso for a $\mathrm{CoN}$, whether they were setting up, modifying or buying a health establishment, increasing bed numbers, acquiring expensive technology, or just simply continuing to practise in the same place. The legal animal (hatched as provisions 36 - 40 of the National Health Amendment Act) has a noble purpose - to meet the government's constitutional obligations of progressive and universal access to healthcare. However, its penalties are anything but benign - 5 years' imprisonment and/or a fine for noncompliance.

Pearmain said it was possible to filter patients through primary care, using telephone advice and interactive information services, sharing knowledge and community agencies. The location of doctors' practices, particularly those of specialists, would always depend on the proximity of technology, whether this was the basics of electricity and running water or a private laboratory. 'No private provider can logically be expected to set up a practice or a hospital in a place where there is a scarcity of patients and in the absence of other incentives', she said.

\section{Specialists predict dire consequences}

Dr Chris Archer, CEO of the South African Private Practitioners Forum, predicted negative consequences for the country's healthcare system if the $\mathrm{CoN}$ legislation was revived with no amendments except for the application date - as is expected. Citing increased costs, decreased competition and higher barriers to entry in the USA after a similar system was introduced, he said that local judges in the relatively recent dispensing doctors Constitutional Court challenge had wanted to know how restricting the number of providers in an area (through licensing) actually promoted access to healthcare services. Echoing Pearmain, Archer said that new technology and restructuring the private health system with outreach satellites would help connect rural and urban areas. Technology was the one area where the current mismatch between supply and demand would help make resources more accessible. Instead of taking clinicians to outlying areas, technology would bring the work to the specialists. Pearmain said that the key issue was to work out how the country could bring together the pro-poor strength of the public health system with the technical capacity and higher quality of the private healthcare system. She said that European Union laws were aimed at actually freeing up health professionals to move between member states, adding, 'the best aspects of capitalism encourage innovation, reward inefficiency and efficacy and promote quality, enhancing the experience of the consumer'. South Africa's health system was in 'desperate need' of all of these. Government should focus on these aspects of the private sector instead of trying to over-regulate it.

There seemed to be no cohesive plan at national level to manage healthcare demand. Instead, a disproportionate emphasis was placed on the proposed CoN, a supply-side management tool.

\section{Dentists grind their teeth}

Also speaking at the conference, the theme of which was 'Converge, Connect, Co-create - Embracing Change', Maretha Smit, CEO of the South African Dental Association, said there were less restrictive ways to bring healthcare to rural and other underserved geographical areas. These included improved working conditions, incentivised employment, subsidies, rural allowances and tax rebates, plus ensuring that healthcare providers in rural areas could more easily earn continuing professional development (CPD) points. Lowering barriers to entry would encourage more people to consider healthcare careers. Examples included making it easier for foreign-qualified doctors to register (verification criteria 


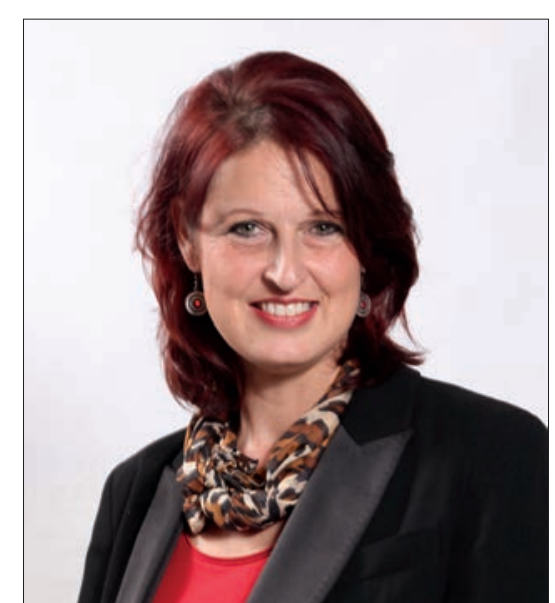

Maretha Smit, CEO of the SA Dental Association.

were recently severely stiffened following intermittent incidents of corrupt and false documentation being submitted to the relevant Medical and Dental Professions Board committee), allowing the private sector to do medical and dental training, training students of rural origin, and allowing the private sector to employ doctors (at present no private hospital may employ a doctor). 'We need to revisit the Health Professions Council of South Africa's ethical rules and engage the private sector to help with facilities management, she asserted.

\section{Pearmain said that the key} issue was to work out how the country could bring together the pro-poor strength of the public health system with the technical capacity and higher quality of the private healthcare system.

Smit expressed concern that the medical profession would become disenfranchised if the CoN went ahead as proposed. 'You have to weigh up the constitutional rights of the patients, establishments and healthcare providers as well as the consumer rights of the patients,' she said. If the certificate was issued 'per facility' it would artificially increase a medical practice's value, leading to more 'seller power'. However, if practitioners themselves were issued with the $\mathrm{CoN}$, the regulations would artificially limit the market, resulting in increased 'buyer power'. With the current critical shortage of healthcare practitioners, overregulation would discourage people from entering the medical profession, increase existing migration overseas and encourage career changes. Backing Pearmain, she said that market forces 'respond most effectively to demand'.

\section{Chris Bateman}

chrisb@hmpg.co.za

S Afr Med J 2014;104(12):841-842.

DOI:10.7196/SAMJ.9119 